\section{IJ§ER}

ISSN: 2149-5939
International Journal of Social Sciences and Education Research

Online, http://dergipark.gov.tr/ijsser

Volume: 3(1), 2017

\title{
Bankaların KOBİ kredileri uygulamaları ${ }^{1}$
}

\author{
SME lending practices of banks
}

\author{
Aysa İpek Erdoğan ${ }^{2}$
}

\begin{abstract}
Received Date: 01 / 09 / 2016
Accepted Date: $15 / 12$ / 2016

$\ddot{\boldsymbol{O}} \boldsymbol{z}$

Bu çalışma bankaların KOBİ kredileri uygulamaları ve kredi karar süreçlerini içerik analizi yöntemiyle incelemektedir. Çalışma için Istanbul ve Ankara'da faaliyet gösteren bankalarda görev yapan on banka yöneticisiyle görüşme yapılmıştır. Görüşmelerde yarı yapılandırılmış derinlemesine görüşme yöntemi uygulanmıştır. Yapılan içerik analizi sonucunda bankaların kredi başvurusu sonrasinda öncelikle şubede bir ön değerlendirme ve istihbarat çalışması yaptığ tespit edilmiștir. Yöneticiler kredi bașvurusu yapan KOBİlerden iş planı istemelerine ră̆men birçok KOBİnin böyle bir plan sunamadiğını ve sonuçta projeksiyonları banka personelinin yapmak durumunda kaldığını ifade etmiştir. Özkaynak yetersizliği, yüksek borçlanma oranı ve firmanın yeni kurulmuş olması kredi başvurusunun olumsuz sonuçlanmasına neden olmaktadır. Bankaların tümü değerlendirme aşamasında kredi skorlama yöntemini kullanmaktadır.
\end{abstract}

Anahtar Sözcükler: KOBİ, KOBİ finansmanı, KOBİ kredileri, Ticari bankalar

\begin{abstract}
This study analyzes the SME lending practices and credit decision procedures of banks with content analysis method. For the study, 10 bank executives who are employed by banks that operate in Istanbul and Ankara were interviewed. Semi-structured in-depth interview technique was used for the interviews. As a result of the content analysis, it was found that banks make a preliminary assessment in the branch and collect financial intelligence after the loan application. The executives declared that although they request business plans from the SMEs that apply for bank loans, most of the SMEs can not present such a plan and the banks' staff are obliged to make the projections. Inadequate equity capital, a high debt ratio and being a newly established firm causes rejection in loan applications. All of the banks use credit scoring method in the evaluation process.
\end{abstract}

Keywords: SME, SME financing, SME loans, Commercial banks

\section{Giriş}

Ekonomik büyüme, girişimciliğin gelişmesi, yeni istihdam alanlarının yaratılması ve yenilikçilik faaliyetleri konusunda KOBİlerin (küçük ve orta büyüklükteki işletmeler) tüm dünya ekonomilerinde önemli bir rolü vardır. Bu işletmelerin kısıtlı dış finansmana ulaşım imkanları içinde banka kredileri çok önemli bir yer tutmaktadır (Petersen ve Rajan, 1994). Banka finansmanına ulaşım KOBİler açısından çok önemli olmasına rağmen literatürde birçok çalışma KOBİlerin banka kredilerine ulaşımda zorluk çektiklerini tespit etmiştir (Hughes, 2009; Beck, DemirgüçKunt ve Maksimovic; 2008; Pissarides, 1999). Literatürde bu firmaların banka kredisine ulaşımda zorluk yaşamasının en önemli nedeninin şeffaf olmamalarından kaynaklanan bilgi asimetrisi problemi olduğu belirtilmektedir (Berger ve Udell, 1998; Stiglitz ve Weiss, 1981). KOBİlerin yüksek başarısızlık oranlarından kaynaklanan yüksek riskleri, yeterli teminatı sağlayamamaları,

${ }^{1} \mathrm{Bu}$ çalışma Boğaziçi Üniversitesi Bilimsel Araştırma Projeleri Fonu tarafından desteklenmiştir. (Proje Kodu: 014N01SUP1, Proje Numaras1: 7945)

${ }^{2}$ Yrd. Doç. Dr., Boğaziçi Üniversitesi, Turizm İşletmeciliği Bölümü, İstanbul, Türkiye, aysa.erdogan@boun.edu.tr 
Erdoğan, A.İ. (2017). Bankaların KOBİ kredileri uygulamaları. International Journal of Social Sciences and Education Research, 3(1), 241-249.

özkaynak yetersizliği ve piyasalardaki dalgalanmalara hassasiyetleri bankaların KOBİlere kredi verirken tereddütlü davranmalarının diğer nedenleridir (Badulescu, 2010).

Literatürde bankaların KOBİ kredileri karar süreçleri ve uygulamalarını inceleyen oldukça k1sıtlı sayıda çalışma mevcuttur. Bu çalışmalar genellikle küçük ölçekli ve büyük ölçekli bankaların KOBİler ile ilişkilerinde işlem bankacıllğı (transaction lending) ve ilişki bankacılığı (relationship lending) arasında yaptıkları tercih ile ilgilidir. İşlem bankacılı̆̆ında kredi kararında ölçülebilir bilgiler kullanılmaktadır. İlişki bankacılığında ise kredi kararı verirken nitel bilgiler kullanılmaktadır. Nitel bilgiler ise KOBİ ve banka personeli arasında uzun süren iletişim sonucunda toplanır. Diamond (1991) banka ve firma arasındaki güçlü ilişkinin bankanın firmayı daha iyi tanımasına ve bilgi asimetrisinin azalmasına imkan verdiğini belirtmektedir. Behr, Entzian ve Güttler (2011) banka ve firma arasındaki uzun süreli ilişkinin banka kredisine ulaşımı olumlu etkilediğini tespit etmiştir.

Stein (2002) ve Cole, Goldberg ve White (2004) küçük bankalarla müşterileri arasında daha yakın ilişkiler olduğu için bu bankaların ilişki bankacılığı yöntemini kullanmak için daha istekli olduklarını ifade etmiştir. Yazarlar büyük ölçekli bankaların karmaşık iletişim kanallarından dolayı nitel bilgiyi kullanma konusunda sıkıntı yaşadıklarını belirtmiştir. Öte yandan De la Torre, Martinez Peria ve Schmukler (2010) müşterilerine çok sayıda ürün ve hizmet sunan büyük ölçekli bankaların ilişki bankacılığı yöntemini daha başarılı bir şekilde uyguladıklarını tespit etmiştir. Uchida, Udell and Yamori (2012) ise büyük ölçekli bankaların işlem bankacılığı yöntemini uygulamayı tercih etmelerine rağmen nitel bilgiyi işleme ve ilişki bankacılığı uygulama kapasitesine sahip olduklarını göstermiştir.

Feakins (2004) ve De la Torre vd., (2010) bankaların KOBİlere kredi vermeden önce tedarikçileri, müşterileri, daha önce kredi aldıkları bankalar ve kredi kayıt bürolarından bilgi edindiklerini tespit etmiştir. Uchida (2011) bankaların KOBİ kredisi kararlarını firmaların finansal performansının, sağlanan teminatın değerinin ve banka-firma ilişkisinin etkilediğini bulmuştur. Feakins (2004) ise bankanın firmanın satış gelirlerindeki trende, borçluluk oranına, teminatın değerine ve firmanın faizin kazanılma sayısı oranına baktığını tespit etmiştir. Yazar ayrıca bankaların belirlediği kredi skorunun kredi limitini belirlemede etkili olduğunu ifade etmektedir.

KOBİlerin yaşadığı finansman kısıtı üzerine çalışmaları içeren literatüre katkı sağlamak amacını güden bu çalışma, bankaların KOBİ kredileri uygulamalarını içerik analizi yöntemiyle incelemektedir. Çalışma dört bölüm içermektedir. İkinci bölümde veri seti ve araştırma yöntemine yer verilmiştir. Üçüncü bölümde ampirik bulgular sunulmuştur. Dördüncü bölüm ise son değerlendirmeleri kapsamaktadır.

\section{Veri seti ve yöntem}

Çalışma için İstanbul ve Ankara'da faaliyet gösteren 4 bankada görev yapan 10 banka yöneticisi ile yarı yapılandırılmış derinlemesine görüşme yapılmıştır. Örneklem 4 tane şube müdürü, 3 tane KOBİ kredilerinden sorumlu müdür ve 3 tane ticari müşteri ilişkileri müdürü olarak görev yapan yöneticiyi içermektedir. Örnekleme ulaşmak için elverişli örnekleme ve kartopu örnekleme yöntemleri kullanılmıştır. Görüşmeler sonrasında yazılı döküm çıkartılmış ve kodlar, kategoriler ve alt kategoriler oluşturularak içerik analizi yapılmıştır. 
Erdoğan, A.İ. (2017). SME lending practices of banks. International Journal of Social Sciences and Education Research, 3(1), 241-249.

\section{Ampirik bulgular}

Çalışmada bankaların KOBİ kredileri uygulamaları ve kredi karar süreçleri bir ana tema, üç kategori ve belirlenen alt kategorilere indirgenmiştir. Ana tema, kategori ve alt kategoriler Tablo 1'de sunulmaktadır. Ana tema "bankaların KOBİ kredileri uygulamaları ve kredi karar süreçleri”" olarak belirlenmiştir.

Tablo 1. Ana Tema, Kategoriler ve Alt Kategoriler

\begin{tabular}{|c|c|}
\hline Tema 1 & KOBİ Kredileri Uygulamaları ve Kredi Karar Süreçleri \\
\hline \multirow{5}{*}{$\begin{array}{l}\text { Kategori } 1 \\
\text { Alt Kategoriler }\end{array}$} & Kredi başvurusu sonrasında yapılan ön çalışmalar \\
\hline & \\
\hline & Istihbarat çalışması \\
\hline & Şubedeki ön değerlendirme \\
\hline & Plan ve projeksiyon analizi \\
\hline \multirow{6}{*}{$\begin{array}{l}\text { Kategori } 2 \\
\text { Alt Kategoriler }\end{array}$} & Kredi kararını etkileyen faktörler \\
\hline & Mali veriler ve firma yaşı \\
\hline & Firmanın banka ile uzun süre ilişkide olması \\
\hline & Kredi temini sonrasında yapılan takip \\
\hline & Kriz dönemlerinde bankaların yaklaşımı \\
\hline & Firmanın verdiği teminat \\
\hline \multirow{5}{*}{$\begin{array}{l}\text { Kategori } 3 \\
\text { Alt Kategoriler }\end{array}$} & Kullanılan yöntemler \\
\hline & Kredi skorlama \\
\hline & Mali verilerin analizi \\
\hline & Firma ziyareti \\
\hline & Küçük ve büyük ölçekli bankaların yaklaşım farklılıkları \\
\hline
\end{tabular}

Yöneticiler KOBİlerle ilgili soruları sormaya başladığımızda öncelikle cevaplarının KOBİ tanımına bağlı olduğunu ifade etmişlerdir. Bankacılık Düzenleme ve Denetleme Kurumu'nun KOBİ tanımı olduğu ve KOBİ tanımının bankalar arasında da farklılık gösterdiği belirtilmektedir. Bankanın KOBİ kredisi kararlarında KOBİlerin arasındaki farkların da önemli olduğu eklenmiştir. Banka yöneticileri kredi başvurusunda bulunan 10-50 arasında çalışanı olan KOBİlerin ortalama \% 50'sinin kredi kararının olumlu sonuçlandığını ifade etmiştir. Yöneticilerin tümü kredi başvuruları reddedildiği takdirde nedeninin firmaya bildirildiğini belirtmiştir.

\subsection{Kredi başvurusu sonrasında yapılan ön çalışmalar}

Bankalarda KOBİ kredisi başvurularında başvuru sonrasında her zaman şubede bir ön değerlendirme yapılmaktadır. Şube personelinin ön değerlendirmeyi yapmak için gerekli mali analiz eğitimlerini aldı $\breve{g} 1$ ifade edilmiştir.

Banka başvuru sonrasında istihbarat çalışması da yapmaktadır. Bu çalışmada daha önce kullanılmış kredilerin düzenli ödenip ödenmediği, firmanın yazılmış çeki ve haciz kaydı olup olmadığı araştırılmaktadır. Piyasa istihbaratı çerçevesinde firmanın mal aldığg ve mal sattığı müşterilerden de bilgi alınmaktadır. 
Erdoğan, A.İ. (2017). Bankaların KOBİ kredileri uygulamaları. International Journal of Social Sciences and Education Research, 3(1), 241-249.

Görüştüğümüz yöneticilerden sadece bir tanesi firmanın gelecekle ilgili stratejik, finansal, üretim ve yatırım hedeflerini içeren beş yıllık iş planı istediklerini belirtmiştir. Diğer yöneticiler iş planının 1-3 yıl için ve orta ve uzun vadeli kredi talepleri karşısında istendiğini belirtmiştir. Detaylı iş planı istemediğini belirten bir banka yöneticisi şöyle demiştir:

"Kredi başvurusunda bulunan firmaya 'Önümüzdeki beş yıllık planın nedir, bu sürede ciron ne olabilir, yatırım yapmayı planlıyor musunuz, şube açacak mısınız?’ gibi sorular soruyoruz.”

Bir diğer banka yöneticisi de şöyle demiştir:

"Firma kiradadır, firma sahibi iş yeri almak isteyebilir. Araç almayı planlıyordur. Bu bilgileri edinmeye çalışıyoruz."

Banka yöneticileri KOBİlerin kredi talep etmelerine rağmen o krediye neden ihtiyaçlarının olduğunu farkında olmadıklarını belirtmiştir. Birçok KOBİnin plan ve projeksiyonlarının olmadığ 1 ve neyi yapıp neyi yapamayacaklarını da farkında olmadıkları vurgulanmıştır. KOBìler ortaya projeksiyon koyamıyorsa değer belirlemek için bankacının tecrübesi devreye girmektedir ve bu da zorlu ve zaman alıcı bir süreçtir. Bir banka yöneticisi şöyle demiştir:

"KOBİ ortaya bir projeksiyon da koyamıyorsa, durumunu gidip bankacı anlayacak."

Bazı KOBİ yöneticileri plan ve projeksiyonları sözlü olarak açıklamasına rağmen kağıda dökememektedir. $\mathrm{Bu}$ durumda banka personeli yönetici ile yapılan görüşme sonrasında projeksiyonu kendi yapıp değer belirlemektedir.

KOBİ skalasının üst kısmının faydalandığı yatırım kredilerinde satın alınan varlıkları ikinci elde nakde dönüştürmek kolay olmadığından dolayı banka personelinin projeleri iyi analiz etmesi ve nakit akımı tahmini yapması gerektiği belirtilmektedir.

Eğer KOBİnin bir fabrikası varsa KOBİ danışmanlarla çalışmaktadır ve işin arkasında bir ekibin varlığı söz konusudur. Böyle bir durumda KOBİnin iş planı da olacaktır. İş planı ve projeksiyonların olması bankanın kredi kararını kolaylaştırmaktadır.

\subsection{Kredi kararını etkileyen faktörler}

Özkaynak yetersizliği, borçlanma oranının yüksek olması ve firmanın yeni kurulan bir firma olması kredi başvurusunun olumsuz sonuçlanmasına neden olmaktadır. Bunun dışında Kredi Kayıt Bürosu skorunun ve firma ortaklarının kredibilitesinin düşük olması da kredi başvurusunun olumsuz sonuçlanma nedenlerindendir.

Banka yöneticilerinin tümü kredi temininden sonra firmanın finansal durumunun takip edildiğini belirtmiştir. Firmalardan üç aylık mali verilerinin ve yıllık vergi beyannamelerinin talep edildiği vurgulanmaktadır. Firma ziyaretlerine ve piyasa istihbaratına da kredi geri ödeme dönemi sürecinde devam edilmektedir.

KOBİ banka ile kredi dışında başka ürünler için de ilişki halindeyse kredi alabilmesi daha kolaydır. Bir banka yöneticisi şöyle demiştir:

"KOBİ gelsin EFT yapsın, banka para kazansın. KOBİler başka ürünler de alınca fiyat ve risk primini arttırmayı."

Banka yöneticilerinin tamamı kredi başvurusu yapan KOBİler arasında uzun zamandır bankalarıyla çalışan işletmelerin sayısal analiz için daha fazla veri sunmuş oldukları ve ödeme düzenleri 
ve nakit akışları görülmüş olduğu için avantajlı olduklarını belirtmişlerdir. Eski müşteriler için kurallar esnetilir, fiyatlamada ve teminat tipi üzerinde daha kolay anlaşma sağlanır. Kredi kararı da daha çabuk sonuçlanır. Bir yönetici durumu şu şekilde açıklamıştır:

"Sistem kredi teklifi hazırlanırken firma ile bankanın kredi çalışma süresi artıkça ek puan vermektedir."

Diğer bir yönetici ise şöyle demiştir:

"Uzun süreli çalışılmış olan firmanın bankada kredi limiti oluşmuştur."

Yöneticiler verilen kredinin vadesinin firmanın sunabildiği teminata bağlı olduğunu belirtmiştir. Kısa vadeli işletme sermayesinin finansmanı için temin edilecek kredi için teminat olarak nakde dönüştürülebilir kıymetli evrak (çek, senet vb.), uzun vadeli kredide ise gayrimenkul ipoteği istenmektedir.

Yöneticiler kriz dönemlerinde bankaların KOBİlere kredi temini yaklaşımlarında farklılıklar olduğunu belirtmektedir. Kriz dönemlerinde bankaların daha seçici olduğu, risk iştahının azaldığı ve limitlerin küçültüldüğü vurgulanmıştır. Bir banka yöneticisi şöyle demiştir:

"Kriz dönemlerinde yeni kredilerde daha dikkatli çalışııı. Teminatı arttırııı. Değerlendirme kriterlerini ise sıkılaştırırız."

Bankaların faizlerin artış gösterdiği dönemde kısa vadeli kredi, faizlerin düşüş gösterdiği dönemde ise uzun vadeli kredi vermeyi tercih ettiğinden bahsedilmektedir. Kredi kararında kredi limiti ve firmanın cirosu arasında uyum olmasına dikkat edildiği belirtilmektedir.

\subsection{Kullanılan yöntemler}

KOBİlere kredi verirken sayısal olarak analiz edebilme imkanı bankalar için çok önemlidir. Banka yöneticileri KOBİlerin faaliyetlerinin doğru bir şekilde kayıt altına alınmamasından dolayı finansal olarak ölçüm yapmanın neredeyse olanaksız olduğunu belirtmişlerdir.

Bankanın firmanın harcama bilgilerine ulaşabilmesi de firma büyüklüğ̈̈ hakkında fikir sahibi olabilmek için çok önemlidir. Fakat banka yöneticileri gelişmekte olan ülkelerde bu bilgilere ulaşma imkanının kısıtlı olduğundan bahsetmişlerdir. KOBİ kredisi kararlarında firmanın gelir ve giderini tahmin edememek bankacılar için zorluk yaratmaktadır. Bu noktada da banka personelinin bilgisi ve tecrübesi ön plana çıkmaktadır.

Banka yöneticilerinin tümü kredi kararında kredi skorlama yöntemi kullanıldığını belirtmişlerdir. Altı yönetici kredi skorlama yönteminin ilk değerlendirme aşamasında kullanıldığını, birer yönetici ise ek değerlendirme aşamasında ve ana kredilendirme kararını verme aşamasında kullanıldığını belirtmiştir.

Bankaların KOBİlere kredi verirken incelenen evraklardan en önemlilerinin mali veriler (son üç döneme ait bilanço, gelir tablosu, mizan), kurumlar vergisi beyannamesi, Kredi Kayıt Bürosu raporu ve ortakların gayrimenkul dökümü olduğu belirtilmiştir.

Görüştüğümüz altı banka yöneticisi kredi kararının başvuru yapan firmanın yapılan kredi skorlaması sonucunda skoru yeterli çıkarsa belli limitler dahilinde şubede verildiğini ifade etmiştir. Limiti aşan kredi başvuruları ise bölge müdürlüklerinde ve genel müdürlükte değerlendirilmektedir. İki banka yöneticisi şubede kredi kararı verilmediğini vurgulamıştır. 
Erdoğan, A.İ. (2017). Bankaların KOBİ kredileri uygulamaları. International Journal of Social Sciences and Education Research, 3(1), 241-249.

Yöneticilerin tümü kredi başvurusunda bulunan firmalara ziyaret gerçekleştirdiklerini belirtmişlerdir. Bu ziyaretlerde firmanın aktif çalışıp çalışmadığı, işyerinin konumu, stoklarının durumu incelenmektedir. Bir banka yöneticisi şöyle demiştir:

"Genel olarak bir düzen, tertip var mı, telefonlar çalıyor mu diye bakarız. Gelen giden müşterilerin ve firmada çalışanların genel halini de inceleriz."

Diğer iki banka yöneticisi şöyle demiştir:

"Firmanın bulunduğu sektöre özgü sahip olduğu ekipmanlarının modernliğine bakarım."

"Iş̧yerinin dekorasyonuna da bakarım. Ofis çok lüksse etkilenirim."

Banka yöneticilerinin bir kısmı ziyaret esnasında müşterilerle yapılan sohbetlerde de firma hakkında birçok bilgi edindiklerini belirtmişlerdir. Bir banka yöneticisi şöyle demiştir:

"KOBİnin finansal olarak sıkışık olup olmadığı konusunda önemli bilgileri müşterilerden öğrenebiliyoruz."

Banka yöneticilerine hangi tür KOBİlerle ilişki bankacılığg ilişkisine girdiklerini sorduğumuzda yöneticilerin çoğu imalat ve inşaat sanayisinde faaliyet gösteren, kredibilitesi ve nakit akış1 iyi olan firmalarla böyle bir ilişki kurduklarını belirtmiştir. Yöneticilerin bir kısmı ise ihracat yapan ve bu konuda kendini geliştirmeye çalışan KOBİlere de yatırım ve finansman gereksinimleri doğrultusunda bireysel çözümler üreterek yol gösterdikleri ilişki bankacılığı yöntemiyle yaklaştıklarını belirtmişlerdir.

Banka yöneticileri büyük ve küçük ölçekli bankaların KOBİlere kredi temini konusundaki yaklaşımlarında farklılıklar olduğunu vurgulamışlardır. Şube ağlarından dolayı KOBİ finansmanı konusunda daha avantajı ılan büyük ölçekli bankaların daha detaylı ve az risk alan bakış açısıyla kredi kararı verdiği, küçük ölçekli bankaların ise büyüme amacı ile daha fazla risk alabildiği ifade edilmiştir. Teminatlar konusunda da büyük ölçekli bankaların daha katı olduğu eklenmiştir. Bir banka yöneticisi şöyle demiştir:

"Küçük ölçekli bankalar büyük bankaların reddettiği müşterilere daha esnek davranıyorlar."

Bir diğer yönetici ise şöyle demiştir:

"Büyük bankaların talep ettiği teminatı sağlayamayan KOBİler şanslarını bir de küçük ölçekli bankalara başvurarak deniyorlar."

Yöneticiler KOBİlerin ilişki bankacılığı yöntemiyle küçük bankalardan daha fazla kredi temin ettiğini belirtmiştir. Küçük ölçekli bankaların müşteri sayısının daha az olması ve çalışanlarının iş yoğunluğunun daha düşük olması her bir müşteri için daha fazla vakit ayrılabilmesine ve ilişki bankacılı̆̆ı anlayışının uygulanabilmesine olanak tanımaktadır. Bir banka yöneticisi durumu şöyle açıklamıştır:

"Küçük bankada kişiler önemlidir. Büyük bankada sistem önemlidir."

Banka yöneticilerinden yedi tanesi risk analizi ile ilgili çalışanları olduğu ifade etmiştir.

\section{Sonuç}

$\mathrm{Bu}$ çalışmada bankaların KOBİ kredileri uygulamaları hakkında banka yöneticileriyle yapılan yarı yapılandırılmış derinlemesine görüşmeler için içerik analizi yöntemi uygulanmıştır. Çalışma 
için Ankara ve İstanbul'da faaliyet gösteren bankalarda görev yapan on banka yöneticisi ile görüşmeler yapılmıştır. İçerik analizi sonucunda uygulamalar ve süreçler üç kategoriye indirgenmiştir. Bu kategoriler kredi kararı sonrasında yapılan ön çalışmalar, kredi kararını etkileyen faktörler ve kullanılan yöntemlerdir.

Banka kredi başvurusu sonrasında her zaman ön değerlendirmeyi şubede yapmaktadır. Ön değerlendirmenin yanı sıra firma ile ilgili istihbarat çalışması da yapılmaktadır. Banka personeli KOBİnin yeterli plan ve projeksiyonu yoksa projeksiyon da yapmak durumundadır.

Firmanın özkaynak yetersizliği, yüksek borçlanma oranı ve yeni kurulmuş olması kredi başvurusunun reddedilmesinin en önemli nedenlerindendir. Kredi verildikten sonra firmanın finansal durumu banka tarafından takip edilmektedir. Kredi başvurusu yapan ve uzun zamandır aynı bankayla çalışan KOBİler her zaman ilk başvurusunu yapan KOBİlere göre avantajlıdır. Kriz dönemlerinde bankaların her zaman daha seçici olduğu ve risk iştahının azaldığı belirtilmiştir.

Banka yöneticilerinin tümü kredi kararında kredi skorlama yönteminin kullanıldığını ifade etmiştir. Kredi başvurusunda bulunan tüm firmalar ziyaret edilmektedir. Bu ziyaretlerde işyerinin konumu, firmanın aktif çalışıp çalışmadığı ve stoklarının durumu analiz edilmektedir.

Çalışmanın en önemli kısıtı banka yöneticilerinin KOBİ kredisi uygulamaları ve süreçleri ile bilgi verirken çalıştıkları kurumun özel bilgilerini verme endişesi taşıması olmuştur. Bu nedenle yöneticilerin çoğunluğu birçok soruya yeteri kadar detaylı olmayan cevaplar vermeyi tercih etmiştir. Sorduğumuz soruya cevap vermek istemediğini belirten banka yöneticileri de olmuştur. Buna rağmen bu çalışma literatürde seyrek rastlanan bankaların KOBİ kredisi karar süreçleriyle ilgili çalışmaların sonuçlarına önemli bir katkı yapmaktadır. Çalışmanın daha geniş bir örneklemle tekrarlanması ve daha detaylı sonuçlar için ayrıntılı sorular içeren bir araştırma yapılması gelecekte yapılabilecek çalışmalara önemli bir örnektir.

\section{Teșekkür}

$\mathrm{Bu}$ çalışma Boğaziçi Üniversitesi Bilimsel Araştırma Projeleri Fonu tarafından desteklenmiştir. (Proje Kodu: 014N01SUP1, Proje Numaras1: 7945)

\section{Kaynakça}

Badulescu, D. (2010). SMEs Financing: The Extent of Need and the Responses of Different Credit Structures. Theoretical and Applied Economics, 17(7): 25-36.

Beck, T., Demirgüç-Kunt, A., \& Maksimovic, V. (2008). Financing Patterns Around the World: Are Small Firms Different? Journal of Financial Economics, 89(3): 467-487.

Behr, P., Entzian, A., \& Güttler, A. (2011). How Do the Lending Relationships Affect Access to Credit and Loan Conditions in Microlending? Journal of Banking and Finance, 35(8): 2169-2178.

Berger, A.N., \& Udell, G.F. (1998). The Economics of Small Business Finance: The Roles of Private Equity and Debt Markets in the Financial Growth Cycle. Journal of Banking and Finance, 22(6): 613-673.

Cole, R.A., Goldberg, L.G., \& White, L.J. (2004). Cookie Cutter vs. Character: The Micro Structure of Small Business Lending by Large and Small Banks. Journal of Financial and Quantitative Analysis, 39(2): 227-251.

De la Torre, A., Martinez Peria, M.S., \& Schmukler, S.L. (2010). Bank Involvement with SMEs: Beyond Relationship Lending. Journal of Banking and Finance, 34(9): 2280-2293. 
Erdoğan, A.İ. (2017). Bankaların KOBİ kredileri uygulamaları. International Journal of Social Sciences and Education Research, 3(1), 241-249.

Diamond, D.W. (1991). Monitoring and Reputation: The Choice between Bank Loans and Directly Placed Debt. Journal of Political Economy, 99(4): 689-721.

Feakins, M. (2004). Commercial Bank Lending to SMEs in Poland. Small Business Economics, 23(1): 5170.

Hughes, A. (2009). Hunting the Snark: Some Reflections on the U.K. Experience of Support for the Small Business Sector. Innovation: Management, Policy and Practice, 11(1): 114-126.

Petersen, M.A., \& Rajan, R.G. (1994). The Benefits of Lending Relationships: Evidence from Small Business Data. The Journal of Finance, 49(1): 3-37.

Pissarides, F. (1999). Is Lack of Funds the Main Obstacle to Growth? EBRD's Experience with Small- and Medium-Sized Businesses in Central and Eastern Europe. Journal of Business Venturing, 14(5\&6): 519539.

Stein, J.C. (2002). Information Production and Capital Allocation: Decentralized versus Hierarchical Firms. The Journal of Finance, 57(5): 1891-1921.

Stiglitz, J.E., \& Weiss, A. (1981). Credit Rationing in Markets with Imperfect Information. American Economic Review, 71(3): 393-410.

Uchida, H. (2011). What Do Banks Evaluate When They Screen Borrowers? Soft Information, Hard Information and Collateral. Journal of Financial Services Research, 40(1-2): 29-48.

Uchida, H., Udell, G.F., \& Yamori, N. (2012). Loan Officers and Relationship Lending to SMEs. Journal of Financial Intermediation, 21(1): 97-122.

\section{Extended abstract in English}

SMEs are important for all world economies because of their contribution to economic development, job creation and innovative activities. Access to bank loans is critical for SMEs to develop and grow. However, barriers to bank loans are considered to be one of the most important constraints encountered by SMEs. Several studies in the literature suggests that SMEs face greater difficulties in their access to bank financing than large firms.

The reluctance of banks to provide loans to SMEs is caused by the information asymmetry that results from inadequate accounting records. Moreover, the high failure rates of SMEs, inability of SMEs to provide adequate collateral and their high sensitivity to economic fluctuations are considered to be the other reasons that makes the banks reluctant to lend to SMEs. Banks are also unable to evaluate whether the SMEs can create sufficient cash flows to repay their loans. Some studies argue that the success rate in SME loan applications is low because small firms generally do not have long term connections with banks that help them to establish reputational capital. There are also studies that argue that banks are reluctant to lend to SMEs because lending to small firms decreases the profit margins as a result of high fixed costs of providing loans to them. The difficulties faced by emerging market SMEs in access to bank loans is even more serious because these firms prefer to operate outside the formal system and this increases the information asymmetry between the SMEs and the bank.

In the literature, there are a limited number of studies that analyze the SME lending practices of banks. These studies generally analyze whether small sized banks and large sized banks prefer transaction lending or relationship lending when they are dealing with SMEs. To contribute to the literature on SME financing constraints, we examine the SME lending practices of Turkish banks with content analysis method in this paper. For the study, we interview 10 bank executives who are employed by banks that operate in İstanbul and Ankara. Semi-structured in-depth interview 
technique is used for the interviews. The sample includes 4 branch managers, 3 managers that are responsible from SME loans and 3 managers that are responsible from commercial loans. After conducting the interviews, all interviews are transcribed verbatim and content analysis is done to determine the main theme, codes, categories and subcategories. The main theme is determined to be SME lending practices and credit decision procedures. The three categories are preliminary work done after the loan application, factors affecting the credit decision and methods used in the decision process.

When we start the interviews, the managers primarily tell that the answers to the questions we ask depend on the definition of the SME term. They say that banks may have different definitions for the term. As a result of the analysis, we find that banks make a preliminary assessment in the branch and collect financial intelligence after the loan application. Information about the firm is also gathered from the customers and suppliers of the firm within the market inquiry.

The managers say that although they request business plans from the SMEs that make a loan application, most of the SMEs can not present such a plan and the banks' staff are obliged to make the projections. If the SME has production units, it should be working with consultants and there is a team behind all the effort. In such a case, the SME will have a business plan. The existence of a business plan and projections makes it easier for a bank to give a credit decision. The managers declare that although majority of the SMEs demand bank credit, they do not really know why they need that credit and how they can use the funds generated by the credit appropriately. The SMEs are also not aware of what they can accomplish and what they can not accomplish.

Inadequate equity capital, a high debt ratio and being a newly established firm causes rejection in loan applications. All the managers say that the financial situation of the firm is followed after providing the loan to the SME. All of the banks use credit scoring method in the evaluation process. All the managers tell that a visit is done to the firm that makes a credit application. The managers tell that conversations done with the customers of the firm during the visit are very useful and they can learn a lot of information about the loan applicant as a result of these conversations. 